\title{
The cooling effect by adsorption-desorption cycles
}

\author{
Eliza Wolak $^{1, *}$ \\ ${ }^{1}$ AGH University of Science and Technology, Faculty of Energy and Fuels, Cracow, Poland
}

\begin{abstract}
Adsorption appliances may turn out to be an alternative to compression-type refrigerators. The adsorption refrigeration machine may be driven by a low-grade heat source, especially solar energy. Solar adsorption cooling systems are environment-friendly and have zero ozone depletion potential. Therefore, the adsorption refrigeration is one kind of energy saving refrigeration methods. The merits of the adsorption refrigeration systems will be more significant especially when it is used in vehicles (automobiles, ships and locomotives), to preserve food and medicines and in air-conditioning. The paper presents the advantages and disadvantages as well as the evolution of the technology of adsorptive refrigeration systems. The methods of improving of adsorption refrigeration systems through improvements in adsorbents properties, use of advanced cycles and hybrid systems is also presented. Possible applications and perspectives for development of adsorption cooling systems are also analyzed. The paper describes a test stand of the adsorption-desorption refrigeration. The present investigations have been carried out utilizing the activated carbon granules as an adsorbent and methanol as an adsorbate. The paper demonstrates the measurement of temperature changes in the adsorbent bed and condenser during adsorption-desorption cycles.
\end{abstract}

\section{Introduction}

The energy problem has already been known since the global energy crisis broke out in the 1970 s. In the process of the primary energy utilization a great amount of waste heat is discharged into the environment. The emission of the waste heat causes energy loss and also thermal pollution. The growing energy demand and the global climate change are compelling reasons to look for effective utilization of waste thermal energy and renewable energy resources. It is assumed that approximately fifteen percent of all the electricity produced in the whole world is utilized for refrigeration and air-conditioning processes of various kinds, and the energy consumption for air-conditioning systems has recently been estimated to constitute $45 \%$ of the whole households and commercial buildings [1].

In times of the energy crisis the quest for and recovery of thermal energy are particularly justified in the case of high levels of sunlight exposure and limited access to electrical energy. Utilisation of solar energy and low-grade waste heat in heat-driven refrigeration cycle is an attractive option. Solar-powered adsorption cooling systems do not have global warming

\footnotetext{
*Corresponding author: eklimows@agh.edu.pl
} 
potential. Solar energy is clean and environmentally friendly. The adsorption refrigeration machine may be driven by a low-grade heat source. The waste heat (engine exhaust, industrial waste heat etc.) can be effectively utilized in adsorption air conditioning and cooling systems. It can be more significant especially when it is used in vehicles (ships, locomotives and automobiles).

The wide development of adsorption refrigeration systems using solid adsorbents occurred since 1970s. Since then, much theoretical and experimental work about adsorption cooling systems has been proposed and developed. The early research work studied the performance of the adsorbent - refrigerant pairs $[2,3]$. They improved the basic theory of adsorption refrigeration with typical adsorbents: mainly on activated carbon, zeolite, silica gel, $\mathrm{CaCl}_{2}$ and the refrigerants were mainly methanol, water, ammonia, hydrogen. New cycles, new systems and methods are proposed to improve heat and mass transfer, increase of COP (coefficient of performance) and decrease of the costs. In the last 20 years studies on the adsorption refrigeration systems have been conducted in France, USA, Japan, India, China and other countries. The main topics are enhancement of heat and mass transfer performance, new system design and its utilization. With the progress of adsorption refrigeration technology, some silica gel-water adsorption chillers have been commercialized successfully on the market.

\section{Adsorption refrigeration cycles}

The adsorption refrigeration cycles may be divided into intermittent cycles and continuous cycles. The wide classification of various adsorption cycles is shown in Fig. 1.

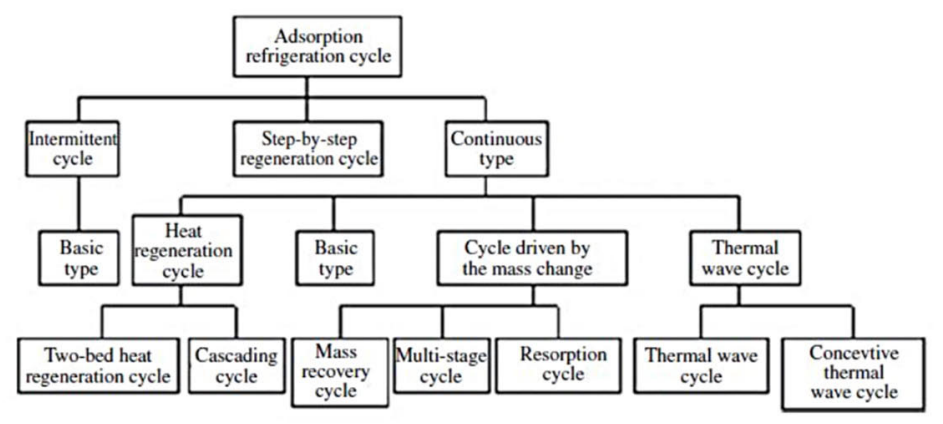

Fig.1. Classification of the adsorption refrigeration cycle [4].

The earliest cycle is the single-bed intermittent cycle. For one bed utilized in the adsorption refrigeration system on condition that only the heating and desorbing process as well as cooling and adsorbing process are involved, it is defined as the basic adsorption refrigeration cycle. This cycle is very simple and mostly used in the solar powered refrigerator. A basic intermittent adsorption refrigeration cycle consists of adsorber/regenerator with adsorbent bed, a condenser and an evaporator. The efficiency of the basic cycle is very low and the cooling is not continuous. The problem of the low COP value (sometimes less than 0.1 ) was mainly caused by the big temperature fluctuation of the adsorption bed [5].

For the continuous refrigeration cycles there are two or more adsorbent beds running alternately. More adsorbent beds can ensure that at any time at least one of them is at the cooling and adsorption stage, for which the cooling power can be output continually. The two-bed operating system is generally used in the cycle when the desorption time is the same as the adsorption time. When the optimum adsorption time differs significantly from the 
optimum desorption time, the multi-bed system may be used. In order to improve the efficiency and practicability of the adsorption refrigeration cycles, many various advanced adsorption refrigeration cycles were proposed in the literature. One can distinguish the following advanced adsorption cycles: heat recovery cycle, mass recovery cycle, thermal wave cycle, convective thermal wave cycle, cascade cycles $[4,6]$.

\subsection{Heat recovery cycle}

The COP value may also be increased by the improvement in energy use - delivered and emitted during the process. For that reason, adsorption cycles for systems consisting of at least two adsorbent beds were worked out. The heat recovery process is generally operated at the switching time for adsorption and desorption processes and may recover the sensible heat to improve the efficiency. After switching between adsorption and desorption, the cooling or heating medium immediately circulates between the hot adsorber and cold adsorber in a closed loop. Then a part of the sensible heat of the hot adsorber recovers. The refrigeration cycle's COP with heat recovery is significantly larger than that of the cycle without the heat recovery process. It can improve COP by $25 \%$ [6].

\subsection{Mass recovery cycle}

The mass recovery cycle may greatly improve the system performance, compared with the conventional cycle powered by low temperature heat [7]. The process involves changing the pressure in adsorbent beds. In the cold adsorbent bed connected with the evaporator the pressure is close to the evaporation pressure, while it is much lower than the condensing pressure. Meanwhile, in the hot adsorbent bed connected with the condenser the pressure is close to the condensing pressure that is much higher than evaporation pressure. In these conditions, connecting the hot bed with cold bed at the switching time may greatly increase the desorption rate of the hot bed, which will be helpful for the improvement of the adsorption quantity of the hot bed in the next half cycle for the cooling and adsorption process. The principle of the mass recovery cycle is shown in Fig. 2.

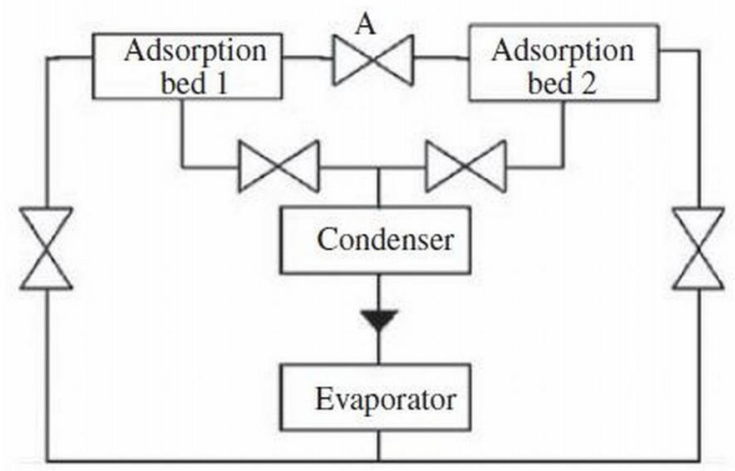

Fig. 2. Principle of the mass recovery cycle [4].

When the desorption process of adsorbent bed 1 completes, the adsorption process of adsorbent bed 2 also finishes. Then the valves connecting the adsorption beds, evaporator, and condenser, and open valve A for mass recovery between the high-pressure adsorbent bed (hot bed) and low-pressure adsorbent bed (cold bed) are closed. The mass recovery will proceed between two beds. 
The heat and mass recovery cycle is currently one of the most commonly and successfully used cycles.

\subsection{Thermal wave cycle}

The use of the thermal wave cycle in the adsorption system was first proposed by Shelton [4]. The merits of a thermal wave cycle is that the heat can be transferred from the hot adsorbent bed to the cold adsorbent bed because the difference in temperature is large. The comparison of the continuous cycle and the thermal wave cycle is shown in Fig. 3.

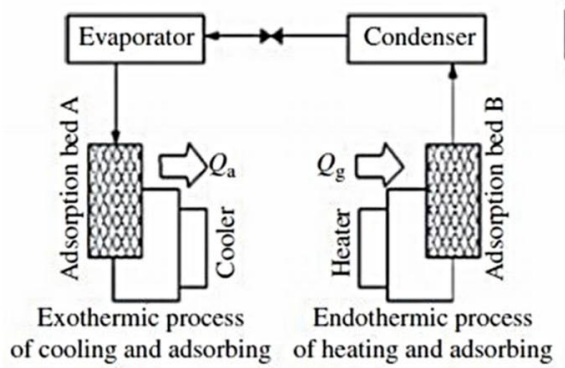

(a)

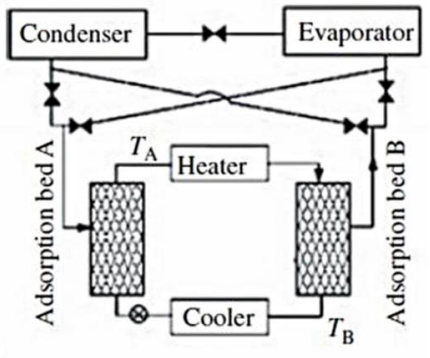

(b)

Fig. 3. Schematic of heat flow a) Basic cycle b) Thermal wave cycle [4].

In the continuous adsorption refrigeration cycle adsorption and desorption processes proceed alternatively. When one of the beds is heated by the external heat source for desorption, the second bed is also cooled by an external cooling source for adsorption. The concept of the thermal wave stipulates that heat is effectively utilized and that the external heat source, which is necessary for the desorption process, is greatly reduced. $80 \%$ of heat required in the desorption process may be provided by the heat released in the adsorption process. The basic principle of such a cycle is using single heating and cooling fluid circuit to connect two adsorbent beds, the cooler and the heater. The circuit of the fluid may transfer the released heat from the adsorption bed to the desorption bed, and recover the adsorption heat for the improvement of the energy efficiency of the system.

\subsection{Convective thermal wave cycle}

In the literature [9] Critoph proposed as an improvement to the thermal wave cycle a pioneering method, which is the convective thermal wave cycle. In this concept the refrigerant acts as the heat transfer fluid. Instead of heating the bed directly, the refrigerant is first heated outside the bed and then circulated through the bed to heat up the adsorbent. Such a cycle uses the forced convection between the refrigerant gas and adsorbent, that is the adsorbent is directly heated or cooled by the high pressure refrigerant vapor to obtain a higher heat density. This solution requires the use of pumps forcing the refrigerant circuit. According to Critoph, the theoretical COP value of the forced convective thermal wave cycle reaches 0.9 at the evaporating temperature of $9^{\circ} \mathrm{C}$, the condensing temperature of $40^{\circ} \mathrm{C}$, and desorption temperature of $200^{\circ} \mathrm{C}$. 


\subsection{Cascade cycles}

In cascading cycles, different working pairs are used in different temperatures ranges. The main characteristic of the cycle is that the heat will be transferred from the working pair with a higher equilibrium adsorption/desorption temperature to the working pair with the lower equilibrium adsorption/desorption temperature. These are applied when there exists a high temperature gradient between the heat source and the evaporator/refrigeration space. Douss and Meunier [ 10] conducted their studies on the basis of a cascading adsorptive heat pump. They worked on the activated carbon-methanol intermittent cycle and the two adsorber zeolite-water cycle. Driving heat was supplied by an external heat source to zeolite adsorbers while activated carbon adsorber was heated by heat recovered from zeolite adsorber under adsorption.

The above-mentioned cycles are still being investigated and developed in order to obtain the best possible effects and cooling capacities. One also attempts to combine the abovementioned cycles with each other. This, however, results in an increase of the complexity of the systems and makes them sophisticated and this it turn affects the failure rate of adsorptive refrigerating appliances. Nevertheless, the advanced adsorption cycles are a promising direction for development of this branch of practical use of the desorption phenomenon.

\section{Commercial application of adsorptive refrigerators}

A significant part of adsorptive refrigerating systems described in the literature involves a prototypical appliance usually made on a small laboratory scale and theoretical models constructed on the basis of experimental data with the aid of computer programs. There are also appliances created on a bigger scale serving until today as air-conditioners for facilities, but they are still a single instance. The development of technology of adsorptive refrigeration is primarily limited by high costs of the design of the equipment and by the still low efficiency of such appliances [11].

The first instances of commercialization of adsorption refrigeration systems occurred in the United States and Japan. The data in Table 1 was collected and presents the commercial use of adsorption refrigeration systems together with a list of the main companies on the market.

Building integrated solar energy systems has the potential to provide a sustainable solution to the ever-increasing demand. They can provide cooling in the summer, heating in the winter and hot water all through the season. The basic idea of the green building is to use renewable natural energy sources (solar, wind, geothermal energy) instead of coal, oil and other fossil fuels. The green building uses the most convenient, non-polluting energy for power generation, heating and refrigeration, as well as to supply hot water to meet living needs. The solar adsorption air-conditioner was used in the Green Building, which was built by the Institute of Building Science Research in Shanghai City [19]. The authors calculated that the payback period of the system would be 5-8 years if the hot water is used for space heating and cooling requirements of the building. If hot water is consumed only for baths or showers for such buildings, the payback period would be reduced to about 2 years.

Certain developed countries initiated the "Climasol-Plan", whose aim is to promote a comprehensive approach to reduce the energy consumption of buildings and the development of passive cooling techniques. They launched certain demonstration projects of solar airconditioners. For example, in 1999, in the Hospital of Freiburg University (Freiburg, Germany), a solar powered silica gel-water adsorption air-conditioning system was installed. 
Table 1. Commercial use of adsorption refrigeration systems.

\begin{tabular}{|c|c|}
\hline Application & Company/utilization \\
\hline \multicolumn{2}{|c|}{ Solar powered systems } \\
\hline Adsorption chiller & $\begin{array}{l}\text { a Japanese company: Nishiyodo Kuchou } \\
\text { Manufacturing (1986) [12] }\end{array}$ \\
\hline $\begin{array}{l}\text { Large cooling capacity adsorption } \\
\text { chillers above } 70 \mathrm{~kW} \text { (zeolite - water) }\end{array}$ & $\begin{array}{l}\text { a Japanese company: Mayekawa } \\
\text { Use of waste heat from cogeneration } \\
\text { systems like diesel engines, gas engines, gas } \\
\text { turbines or fuel cells. Mayekawa has already } \\
\text { successfully installed its adsorption chiller in } \\
\text { a shopping mall in Japan. }\end{array}$ \\
\hline $\begin{array}{l}\text { Solar adsorption icemaker (ice makers } \\
\text { and solar refrigerators) }\end{array}$ & a French company: BLM [13] \\
\hline Adsorption chiller & $\begin{array}{l}\text { HIJC ( Heat Integrated Joint Companies) } \\
\text { Company in the USA - a service provider }\end{array}$ \\
\hline Adsorption chiller (silica-gel water) & Nischiyodo Kuchouki Co.Ltd., Japan [4] \\
\hline $\begin{array}{l}\text { CCHP (Cogeneration system for } \\
\text { cooling, heat and power) }\end{array}$ & $\begin{array}{l}\text { For first time installed in Maltester Hospital } \\
\text { in Kammenz of Germany[4] }\end{array}$ \\
\hline $\begin{array}{l}\text { Silica-gel water adsorption refrigeration } \\
\text { chiller }\end{array}$ & Since 2003 Macom Company, Japan [4] \\
\hline $\begin{array}{l}\text { Adsorption CCHP system, powered by } \\
\text { waste heat from a } 185 \mathrm{~kW} \text { diesel engine }\end{array}$ & $\begin{array}{l}\text { Tokai Optical Co.Ltd. in Nagoya of Japan } \\
\text { (2003) [4] }\end{array}$ \\
\hline Solar thermal freezer & Zeotech GmbH, Germany Company (2011) \\
\hline $\begin{array}{l}\text { Adsorption Chiller Aggregates (water- } \\
\text { silica gel chillers) }\end{array}$ & SorTech AG., Germany (2002) [14 \\
\hline Water-zeolite chillers & $\begin{array}{l}\text { InvenSor GmbH is a German company. } \\
\text { Usually employs waste heat from CHP units, } \\
\text { solar installations and industrial production } \\
\text { processes. }\end{array}$ \\
\hline $\begin{array}{l}\text { The Green Building, which was built } \\
\text { by the Institute of Building Science } \\
\text { Research }\end{array}$ & Shanghai City \\
\hline $\begin{array}{l}\text { Solar powered silica gel-water } \\
\text { adsorption air-conditioning system }\end{array}$ & $\begin{array}{l}\text { In 1999, in a Hospital of Freiburg University } \\
\text { (Freiburg, Germany) }\end{array}$ \\
\hline $\begin{array}{l}\text { Solar adsorption air-conditioning } \\
\text { system }\end{array}$ & $\begin{array}{l}\text { A cosmetics company in Sarantis S.A, } \\
\text { Greece }\end{array}$ \\
\hline $\begin{array}{l}\text { The locomotive air conditioner } \\
\text { (zeolite-water) }\end{array}$ & $\begin{array}{l}\text { Air conditioning prototype Shanghai } \\
\text { Railway Bureau }\end{array}$ \\
\hline \multicolumn{2}{|c|}{ Waste thermal energy } \\
\hline $\begin{array}{l}\text { Adsorption refrigeration system for the } \\
\text { production of chilled water (exhaust } \\
\text { gas from the diesel engine of a fishing } \\
\text { boat) zeolite-water }\end{array}$ & Fishing boat [15] \\
\hline $\begin{array}{l}\text { Adsorption air-conditioning system - } \\
\text { engine exhaust gas }\end{array}$ & Automobile [16] \\
\hline $\begin{array}{l}\text { Adsorption air-conditioner (zeolit 13X - } \\
\text { water) }\end{array}$ & $\begin{array}{l}\text { Cooling the interior of cockpit in a } \\
\text { locomotive [17] }\end{array}$ \\
\hline $\begin{array}{l}\text { Adsorption refrigeration cycle } \\
\text { (activated carbon-methanol) }\end{array}$ & $\begin{array}{l}\text { Waste heat from a fuel cell-electric vehicle } \\
\text { [18] }\end{array}$ \\
\hline
\end{tabular}


Another example is the solar silica gel-water adsorption air-conditioning system installed in the cosmetics company in Sarantis S.A, in Greece.

Unfortunately, there are still excessive production costs and insufficient competitiveness compared to the compressor refrigerators. Many companies that produce solar powered adsorption refrigerators have to stop production. For example, SunMark, BLM, Zeopower company (USA), EG Solar (Germany), Solaref (France), unsuccessfully attempted to commercialize intermittent solar adsorption refrigerators using zeolite water pair [20].

\section{Experimental part}

The paper presents the initial measurements of the new testing station. The sketch of testing station is shown in Fig.4. The control study of the newly constructed testing station of the adsorbents in the adsorption refrigeration system was conducted. The system of activated carbon - methanol was studied. The most crucial part of the system is the absorber/regenerator which is a steel tube (dimensions: diameter: $60 \mathrm{~mm}$, wall thickness: 2 $\mathrm{mm}$, length: $270 \mathrm{~mm}$ ). Inside the adsorber there is a grid tube with a diameter of $35 \mathrm{~mm}$ arranged concentrically. The tested adsorbent - activated carbon - formed from a coconut shell, in the amount of approx. $170 \mathrm{~g}$ - was placed inside the adsorber between the steel pipe and the grid tube. Such an arrangement of adsorbent maximizes the contact of the activated carbon - methanol vapor, has a positive influence on the regeneration of the bed, facilitating heat transfer to the adsorbent bed from the outside. The evaporator and the reservoir of excess refrigerant of a thin-walled aluminum may have the volume of $150 \mathrm{ml}$. The adsorber is heated by two band heaters with a diameter of $60 \mathrm{~mm}$ and a length of $135 \mathrm{~mm}$ and the power of 900 $\mathrm{W}$ each. The cooling of the adsorber is carried out using a fan. The adsorber was linked with the evaporator by a $6 \mathrm{~mm}$ polyurethane cable. A system of valves and pipes connecting the adsorber to the evaporator performed the role of a condenser.

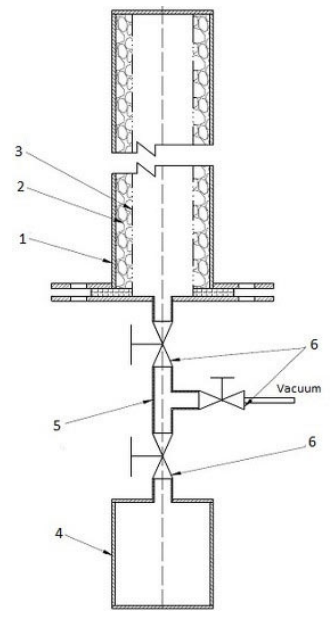

Fig.4. Sketch of testing station of adsorption cooling system 1-adsorber/generator, 2-adsorbent bed, 3-steel grid, 4-evaporator, 5-condenser, 6-valves 


\subsection{Experimental procedure}

Control measurements were designed to check the correctness of the operation test station. A double cycle of adsorption and regeneration of the adsorbent bed was conducted. For comparison's sake, the results of a single adsorption-desorption cycle for the different temperature conditions was also provided.

Before measurements were made, the system was connected to a vacuum pump for a period of 30 minutes and the system pressure was reduced to $-0,9$ bar (according to the indication of the pump pressure gauge). The evaporator was filled with $100 \mathrm{~cm}^{3}$ of methanol and was connected to the system.

The adsorption process was initiated by opening a valve connecting the generator to the evaporator. During the process, the temperature change in the generator and in the evaporator was registered.

After closing the valve separating the generator from the rest of the system (after completion of the adsorption process) another process was started - the process of desorption - the process of the regeneration of the adsorbent bed. The desorption process was carried out by heating the generator with a band heater. Temperature was measured electronically using the recorder, which registers changes in temperature sensors in the generator. All sensors are placed at one level in the middle of the bed height.

After completion of the desorption the valve separating the generator was closed. The heater was removed from the surface of the generator and after cooling the system to room temperature the researchers proceeded to the next cycle - the adsorption phase.

Table 2 presents the temperature changes that accompanied adsorption. During the process of adsorption of methanol vapors the heat of adsorption is released on the carbon adsorbent, resulting in an increase in temperature. At the same time heat is absorbed in the condenser therefore the temperature decreases. In the experiment there was an increase of temperature by 13.7 in the first adsorption cycle, and by 11.1 in the second adsorption cycle while the temperature decreases by $5^{\circ} \mathrm{C}$ in the condenser. In a single cycle of temperature an increase was registered in the adsorbent bed equal to 16.6 and the temperature in the condenser fell by 10.4 .

Table 2. The measuring of temperature change in the adsorber and in the condenser

\begin{tabular}{|l|c|c|c|c|c|c|}
\hline & \multicolumn{3}{|c|}{ Adsorber } & \multicolumn{3}{c|}{ Condenser } \\
\hline$\left[{ }^{\circ} \mathrm{C}\right]$ & $\mathrm{T}_{\min }$ & $\mathrm{T}_{\max }$ & $\Delta \mathrm{T}_{\mathrm{a}}$ & $\mathrm{T}_{\min }$ & $\mathrm{T}_{\max }$ & $\Delta \mathrm{T}_{\mathrm{p}}$ \\
\hline \multicolumn{7}{|c|}{ The double adsorption-desorption cycles $\mathrm{T}_{\mathrm{ad}}=28^{\circ} \mathrm{C}$} \\
\hline Adsorption I & 28.0 & 41.7 & 13.7 & 27.8 & 22.9 & 4.9 \\
\hline Adsorption II & 27.2 & 38.3 & 11.1 & 27.2 & 22.5 & 4.7 \\
\hline \multicolumn{7}{|c|}{ A single adsorption-desorption cycle $\mathrm{T}_{\mathrm{ad}}=25^{\circ} \mathrm{C}$} \\
\hline Adsorption & 24.9 & 41.5 & 16.6 & 24.4 & 14.0 & 10.4 \\
\hline
\end{tabular}

For comparison's sake, Fig. 5 presents the temperature change in the adsorbent bed and in the condenser for the two adsorption processes. The adsorption temperature for the first measurement (I) was $25^{\circ} \mathrm{C}$ and for the second measurement (II) it was $28^{\circ} \mathrm{C}$. 


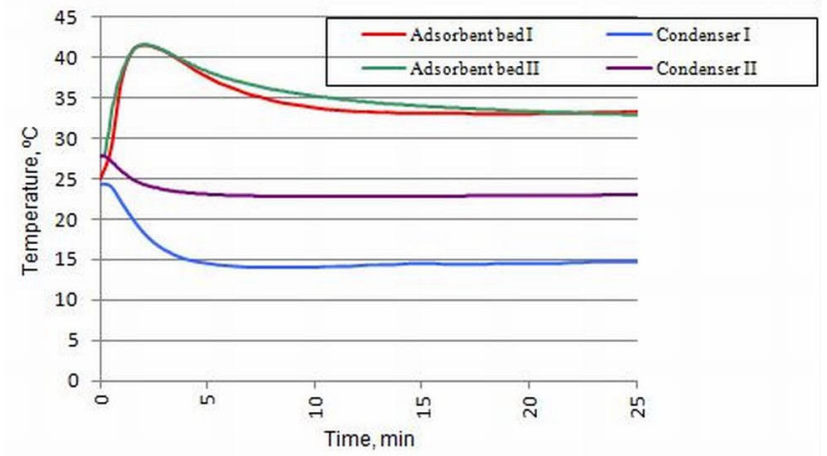

Fig. 5. Temperature profile in the adsorber and condenser during the adsorption cycle.

In accordance with Fig. 5, as a result of adsorption (I) at $25^{\circ} \mathrm{C}$, a lower temperature was obtained in the condenser. For this cycle, the cooling effect is greater. The system cooled by 10.4 degrees. Fig. 6 shows the change in temperature inside the generator during desorption. It takes the system approx. $15 \mathrm{~min}$ to reach the $120^{\circ} \mathrm{C}$ temperature of desorption. The graph shows the warm-up period adsorbent bed to desorption temperature.

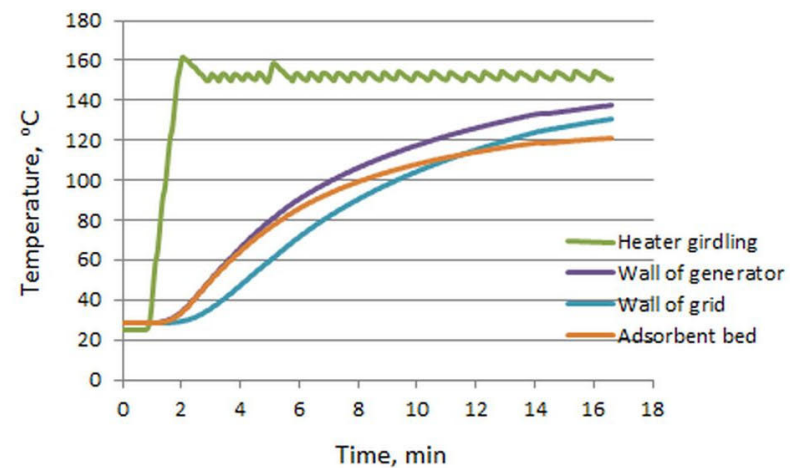

Fig. 6. Temperature changes during desorption process.

\section{Conclusions}

The present experiment demonstrated that it is possible to produce a low temperature by means of a simple mechanism using activated carbon bed for adsorption/desorption methanol. The presented results demonstrate that correct operation was performed at the test station.

After analyzing the initial measurements it was established that the desorption time for the system is $1 \mathrm{~h}$, temp. $120^{\circ} \mathrm{C}$, cooling time deposits: $0.5 \mathrm{~h}$, adsorption time: $0.5 \mathrm{~h}$.

The arrangement that was built requires some refinement and improvement. First of all, one should insulate or isolate the refrigeration area and one should install the pressure sensor inside the system which will enable the researcher, among other things, to calculate the adsorbed amount of the refrigerant in the system. The presented system allows for the effect of adsorption cooling. Further work will involve the increasing of the cooling effects.

The review of commercial applications of adsorptive refrigerators demonstrated that adsorption cooling technologies are attractive alternatives. Environment-friendliness and energy usage-related benefits of this technology are also impressive. However, much effort should be done to resolve the problem of the adsorption cooling, mainly to improve heat 
exchange, to increase COP efficiency and to reduce production costs. Therefore, further work must be done to help solve the above-mentioned problems.

The work was carried out within the research to keep the research potential AGH (11.11.210.244).

\section{References}

1. RK. SurA Das, 1, $190(2010)$

2. R.E. Critoph, Carbon, 27, 63 (1989)

3. N.C. Srivastava, I.W. Eames, App Therm Eng, 18, 707 (1998)

4. R.Wang, L. Wang, J. Wu, Adsorption refrigeration technology (John Wiley \& Sons, Singapur 2014)

5. L.W. Wang, J.Y.Wu, R.Z. Wang, App Therm Eng, 23, 1453 (2003)

6. D. C. Wang, Y. H. Li, D. Li, Y. Z. Xia, J. P. Zhang, ", Renew and Sust Ener Rev, 14, $344(2010)$

7. A. Akahira, K.C.A. Alam,Y. Hamamoto, A. Akisawa, T. Kashiwagi, Int J Refrig, 27, 225 (2004)

8. S.V. Shelton, ASME J Ener Res Tech,112(3), 69 (1990)

9. R.E. Critoph, Heat Recov Sys \& CHP, 14(4), 343 (1994)

10. N. Douss, F. Meunier, Chem Eng Sci, 44(2), 225 (1989)

11. E. Wolak, S. Kraszewski, E3S Web of Conferences (2016) in press

12. http://www.r718.com/news/viewprintable/3530

13. F. Meunier, Appl Therm Eng 61, 830 (2013)

14. http://www.sortech.pl

15. R. Zhu, B. Han, M. Lin, Y.Yu, Int J Refrig, 15 (1), 31( 1992)

16. M. Suzuki, Heat Recov Sys \& CHP, 13(4), 335 (1993)

17. Y. Z. Lu, R. Z. Wang, M. Zhang, S. Jiangzhou, Ener Conv and Manag, 44, 1733(2003)

18. P. Yang, Heat Trans - Asian Res, 39 (7), 523 (2010)

19. R.Z. Wang, X.Q. Zhai, Energy 35(11), 4407 (2010)

20. P. Goyal, P. Baredar, A. Mittal, A.R. Siddiqui, Ren and Sust En Rev, 53, 1389 (2016) 